\title{
Infarctus pulmonaire
}

\section{Pulmonary infarction}

\section{Kam $\cdot$ S. Rhiem $\cdot$ P. Bilbault}

Reçu le 6 avril 2011 ; accepté le 18 mai 2011

(C) SFMU et Springer-Verlag France 2011

Il s'agit d'un patient de 56 ans, sans antécédent, admis de nuit aux urgences pour une douleur thoracique gauche spontanée et insomniante, décrite par lui-même comme étant d'origine " costale ». L'interrogatoire révèle l'existence d'une toux sèche intermittente depuis huit jours. À l'examen clinique, la palpation basithoracique gauche déclenche la même douleur, l'auscultation pulmonaire est normale ainsi que l'ECG. La radiographie pulmonaire montre une opacité triangulaire à base pleurale gauche associée à un pincement intercostal (Fig. 1A, flèche noire). L'angioscanner thoracique spiralé met en évidence des emboles pulmonaires bilatéraux des deux bases (Fig. 1B, flèches blanches), et les fenêtres parenchymateuses révèlent deux infarctus pulmonaires triangulaires à bases périphériques lobaires inférieurs gauches (Fig. 1C, flèches noires).

\section{Kam $\cdot$ P. Bilbault $(\square)$}

Service des urgences, hôpital de Hautepierre, avenue Molière, F-67098 Strasbourg, France e-mail : pascal.bilbault@chru-strasbourg.fr

\section{S. Rhiem}

Pôle de radiologie, hôpital de Hautepierre, avenue Molière, F-67098 Strasbourg, France
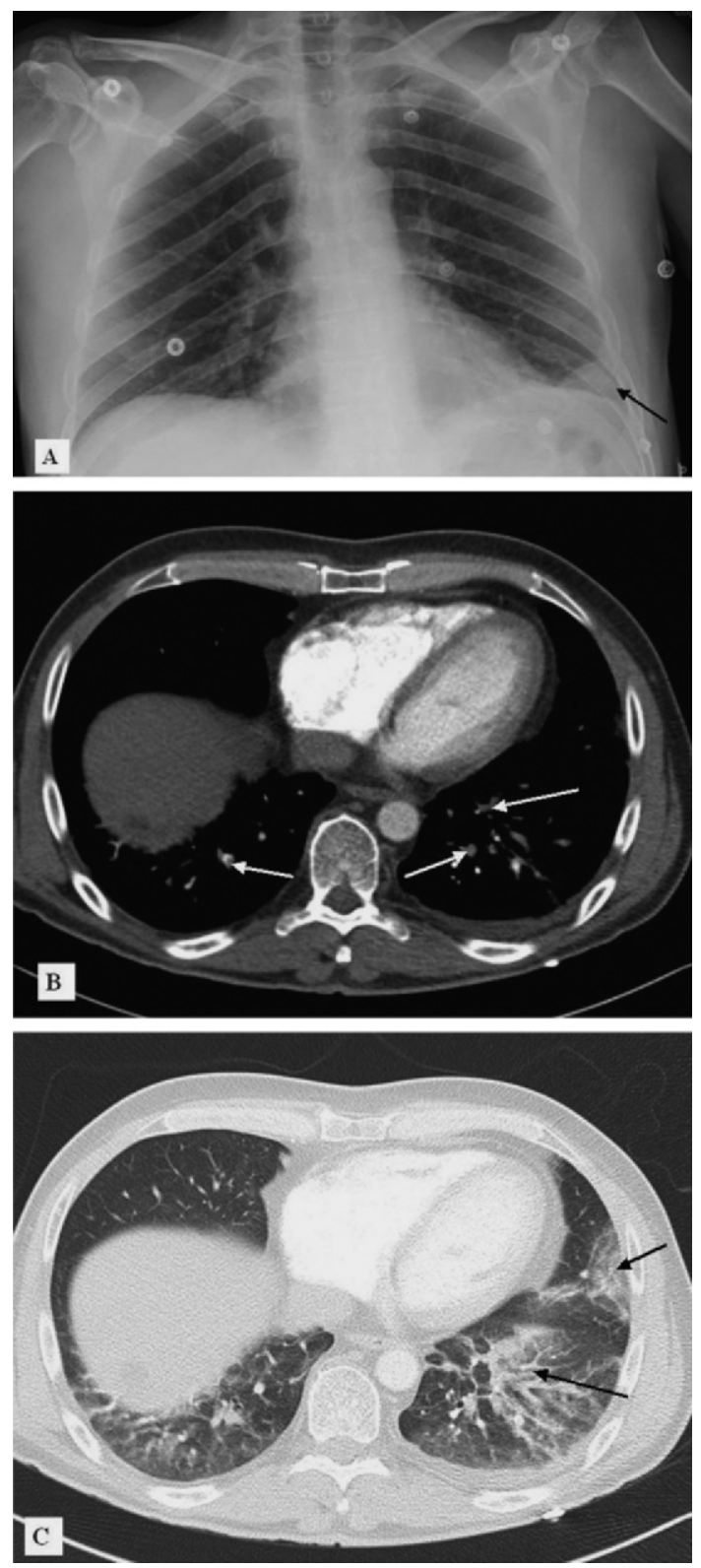

Fig. 1 A : Radiographie pulmonaire ; B : Angio-scanner thoracique spiralé, temps vasculaire ; $\mathrm{C}$ : Angio-scanner thoracique spiralé, fenêtres parenchymateuses 